\title{
A LINGUAGEM COMO FERRAMENTA DO CUIDADO DO ENFERMEIRO EM CIRURGIA CARDÍACA
}

\author{
The Language as a Tool of the Care of \\ the Nurse in Cardiac Surgery \\ El Lenguaje como Herramienta del Cuidado del \\ Enfermero en Cirugía Cardiaca
}

Maria José Coelho

\begin{abstract}
Resumo
Este estudo descreveu a linguagem utilizada no dia-a-dia por enfermeiros em unidade de terapia intensiva cardíaca. Apoiase em uma abordagem qualitativa, descritiva, que utilizou a etnometodologia, envolvendo os conceitos de prática, indicialidade e noção de membro. Para a coleta de dados, foram realizadas observação participante e fotografia para captação da imagem gestual. Os resultados apontam a utilização de palavras científicas, siglas e abreviações, silêncio, gestos e palavras com significado distinto. Essa linguagem é totalmente entendida pelos membros do grupo e se apresenta de forma natural pelos atores sociais; no entanto, não é de domínio do cliente, podendo ocasionar falsas interpretações. Dessa forma, este estudo propõe uma reflexão sobre a importância de utilizar-se no cotidiano uma linguagem compreendida não só pelos profissionais, mas também pelo cliente, para que esta seja uma ferramenta do cuidar/cuidado de enfermagem.
\end{abstract}

Palavras-chave: Enfermagem. Cuidados de Enfermagem. Linguagem.

Abstract

This study described the language used daily by nurses in unit of cardiac intensive therapy. It is about a descriptive qualitative approach that uses the ethnomethodology by encompassing the concepts of practice, indiciality and notion of member. With reference to data gathering, the participant observation and photography were carried out towards capturing the gesture image. The results refer to the use of scientific words, acronyms and abbreviations, silence, gestures, and words with distinct meanings. This language is utterly understood by the group members and is performed in a natural manner by the social actors. However, it is not the client domain to cause fake interpretations. In this light, this study proposes a reflection about the relevance of applying in our daily life a language understood not only by professionals, as well as by the client, in order to be regarded as a tool intended for the nursing care.

\section{Resumen}

En el presente estudio se hace una descripción del lenguaje utilizado por los enfermeros en sus tareas cotidianas en una Unidad de Terapia Intensiva Cardiaca. Es basada en un enfoque cualitativo, descriptivo, que se ha utilizado de la etnometodología, abarcando los conceptos de la práctica e indicialidad. En respecto a colecta de los datos, se ha realizado observación directa y fotografía para se obtener mejor captación de la imagen gestual. Los resultados señalan el empleo de las palabras científicas, siglas y abreviaturas, silencio, gestos y palabras con significado distinto. Ese lenguaje es totalmente comprendido por los miembros del grupo y utilizado de modo natural por los actores sociales, pero no es de dominio del cliente, lo que puede llevar a falsas interpretaciones. Este estudio propone, por lo tanto, una reflexión sobre la importancia de utilizarse, en el cotidiano, un lenguaje que sea comprendido tanto por los profesionales como por el cliente, para que sea un instrumento del cuidar (cuidado de enfermería).

Palabras clave:

Enfermería. Atención de Enfermería. Lenguaje. 


\section{INTRODUÇÃO}

A linguagem que emerge do cotidiano profissional de enfermeiros envolve símbolos e significados oriundos da prática, que fazem parte das situaç̃oes vividas e conhecidas por membros desse grupo. Esses símbolos e significados são apreendidos como verdades e são constituídos através da interação com atores sociais que participam dessa prática.

0 cotidiano do cuidar/cuidado de enfermagem em cirurgia cardíaca se inventa com mil maneiras de fazer esses símbolos e significados e caracteriza-se por ser construído a todo o momento de uma forma própria. Construímos nossas práticas de acordo com o que adquirimos em nosso dia-a-dia, e essa prática coloca em jogo uma apropriação ou reapropriação dessas maneiras de fazer. Instaura, portanto, um presente relativo a um momento e a um lugar'.

Coelho ${ }^{2: 15}$ define o cuidar como sendo o:

...processo de expressão, de reflexão, de elaboração do pensamento, de imaginação, de meditação e de aplicação intelectual, desenvolvido pela enfermeira, em relação às ações mais simples até as mais complexas, $e$ que requer um mínimo de condições estruturais, ambientais e de recursos humanos que seja razoável para assegurar a confiabilidade, a credibilidade dos atos/ações direcionados ao atendimento dos clientes nos niveis imediato, mediato e tardio...

E o cuidado ${ }^{2: 15}$ como:

A ação imediata prestada pela enfermeira ou algum elemento de sua equipe, técnico e/ou auxiliar de enfermagem, em curto espaço de tempo, desenvolvido em vários momentos, envolvendo segurança e competência, aliadas à tecnologia específica que a situação exige...

0 cuidar/cuidado de enfermagem em cirurgia cardíaca é complexo e compreende todas as ações do enfermeiro direcionadas ao cliente desde que este toma conhecimento da cirurgia, através do mapa cirúrgico recebido no dia anterior ao da sua realização, quando se iniciam os cuidados abrangendo as orientações pré-operatórias ao cliente e seus familiares, a montagem da unidade, os cuidados na admissão, a manutenção das funções orgânicas, a observação hemodinâmica, até as instruções relacionadas à alta hospitalar do cliente. ${ }^{3}$

Os grandes avanços tecnológicos ocasionaram um aumento do número de cirurgias cardíacas nos últimos dez anos. Isto se deve, entre outros fatores, à participação e colaboração da equipe de enfermagem que presta cuidado direto e indireto ao cliente. 0 enfermeiro, que tem domínio técnico e científico, exerce funções de cuidado, controle e observação, considerando a complexidade da cirurgia que é realizada ${ }^{4}$.

Ao desenvolver o cuidar/cuidado em cirurgia cardíaca o enfermeiro utiliza como ferramenta a interação com o cliente, caracterizada por toques, palavras e gestos, entre outros símbolos. Na verdade, o enfermeiro utiliza todos os órgãos dos sentidos e talvez nem se dê conta da quantidade de mensagens emitidas ou captadas com olhares, palavras, sorrisos, movimentos corporais, alarmes, sons de vozes e gemidos. Mas os cuidados são realizados a todo o tempo: uns mais complexos, outros menos. Alguns destes cuidados são diretos, como a administração de medicamentos e a coleta de material para exames; outros, indiretos, como o registro nos prontuários, a solicitação de material e o controle de visitas.

No cotidiano de cuidados em cirurgia cardíaca, existe tecnologia de ponta, muita correria e ansiedade, alto nível de adrenalina, risco de morte e, principalmente, gente. E, centrada no ser humano, a Enfermagem realiza sua função precípua que é cuidar de gente. Esse cotidiano envolve a interação entre enfermeiros e clientes necessária para suprir as necessidades humanas básicas dos clientes, como forma de atingir a manutenção dos aspectos fisiológicos e observação de suas respostas aos agressores externos. No entanto, esse cuidar tem características que o tornam distinto, principalmente porque a expectativa quanto à cirurgia gera muita ansiedade e medo nos clientes, exigindo muita atenção, dedicação e conhecimento técnico por parte dos enfermeiros e de suas equipes. ${ }^{5}$

0 enfermeiro precisa encorajar a verbalização do cliente, ouvi-lo, ser compreensivo e proporcionar-Ihe informações que o ajudem a aliviar suas preocupações. Os temores são expressos sob diversas formas, cabendo ao profissional identificar seus significados e utilizar-se de artifícios para minimizá-los. 0 medo do desconhecido, freqüentemente, é o pior de todos. Sendo assim, quanto mais o cliente tiver conhecimento sobre suas possibilidades futuras, melhor será sua adaptação à internação e, conseqüentemente, sua recuperação. 0 enfermeiro deve utilizar a linguagem como preciosa ferramenta para se fazer compreendido e assim atingir a meta da interação humana. Portanto, a linguagem utilizada no cotidiano deve estar inserida no cuidado ${ }^{3}$.

Para melhor compreensão da enfermagem em cirurgia cardíaca, convêm destacar a minha percepção acerca do cuidar, cuidado, linguagem e cotidiano, nesse estudo:

Cuidar é aplicar conhecimentos científicos no dia-a-dia, associados à habilidade de utilizar a emoção e a sensibilidade como bases da comunicação para executar cuidados de enfermagem, considerando o cliente como um ser humano que precisa ser respeitado.

Cuidado é qualquer ação de enfermagem realizada por um membro da equipe que vise o bem-estar físico, mental e espiritual do cliente.

Linguagem é a utilização de símbolos e signos em um determinado contexto situacional. Para que seja uma ferramenta do cuidar/cuidado do enfermeiro, deve fazer parte do processo de interação.

Cotidiano é construído por maneiras diversificadas de cuidar em enfermagem no dia-a-dia da cirurgia cardíaca, considerando os mínimos detalhes dos aspectos interacionais, sendo constituído por mil maneiras de fazer.

Em nossas vivências como enfermeiras e pesquisadoras na área hospitalar, especificamente na Unidade de Terapia Intensiva Cardíaca, temos percebido que a linguagem utilizada por enfermeiros nesse setor apresenta características diferenciadas, principalmente por conter símbolos e significados distintos da linguagem utilizada pela sociedade em geral. A 
ação recíproca do enfermeiro com sua clientela resulta na relação entre estes atores sociais e faz parte do cotidiano do cuidar/cuidado em cirurgia cardíaca. Verificamos, portanto, que, nessa interação, enfermeiros e clientes utilizam linguagens diferenciadas, que se relacionam para a realização dos cuidados de enfermagem. Nesse processo, para que ocorra a troca de informações, um ator deve se colocar no lugar do outro e tentar entendê-lo com o intuito de obter uma reação. Tal processo de ação e reação caracteriza a interação no cotidiano ${ }^{6}$.

No entanto, nessas interações se associam símbolos e significados que emergem da prática profissional e da sociedade em geral. Os enfermeiros, como membros de um grupo que vivenciam uma prática cotidiana no cenário da cirurgia cardíaca, apresentam uma linguagem diferenciada, complexa e rica em símbolos e significados. Esse estudo tem como objeto a linguagem utilizada no cotidiano por enfermeiros que atuam em Unidade de Terapia Intensiva Cardíaca. Entendemos que essa linguagem faz parte do saber científico associado ao senso comum e se apresenta de acordo com a situação vivida.

Apreender os símbolos e significados oriundos da práxis pode possibilitar a descoberta de novos atributos e/ou a reafirmação dos atributos da profissão, com vistas a sua consolidação como ciência ${ }^{7}$. 0 conhecimento da linguagem utilizada no cotidiano do cuidar/cuidado de cirurgia cardíaca amplia os horizontes do saber da Enfermagem nessa área específica, sendo importante para compreensão da realidade que vivenciamos. Esse estudo torna-se relevante porque a prática de Enfermagem requer a identificação dos símbolos e significados utilizados pelos enfermeiros em suas interações nas mais diversas áreas do saber e do fazer profissional.

Diante desses entendimentos, desejamos entender melhor como é a linguagem utilizada no cotidiano pelos enfermeiros que atuam em unidade de terapia intensiva cardíaca. Para desvendar o fenômeno, traçamos o seguinte objetivo:

- Descrever a linguagem utilizada no cotidiano por enfermeiros em unidade de terapia intensiva cardíaca.

\section{METODOLOGIA}

Este estudo constitui uma abordagem qualitativa sobre a linguagem utilizada no cotidiano por enfermeiros em unidade de terapia intensiva cardíaca, considerando que esta faz parte do cuidar/cuidado de enfermagem.

0 método utilizado foi a etnometodologia, que sugere que membros do mesmo grupo dispõem de um saber do senso comum de sua sociedade como saber [...] do que quer que seja $[\ldots]^{8: 52}$. Entendo que enfermeiros que cuidam de clientes em pré e pós-operatório são membros de um mesmo grupo. Assim, estes atores sociais dispõem de um saber sobre a linguagem utilizada no cotidiano.

Este tipo de estudo não se refere aos métodos que os investigadores utilizam para coletar dados, mas à matéria substantiva a ser investigada, que tende aos detalhes relativos à ação e compreensão com conteúdos específicos de comunicação ou interação. Os etnometodólogos tentam compreender o modo como as pessoas percebem, explicam e descrevem a ordem do mundo em que habitam ${ }^{9}$.

As metodologias designadas como [...] raciocínio sociológico prático [...], empregado pelos membros da sociedade e observado na gestão corrente dos seus negócios, vêm a ser o corpus da pesquisa etnometodológica. 8:52 A etnometodologia compreende o estudo da prática que os atores utilizam no diaa-dia, que lhes permitem viver juntos, inclusive de maneira conflitiva, e que regem as relações sociais que mantêm entre si.

Consideramos que este método se adequou perfeitamente ao objeto de estudo porque através dele posso compreender a linguagem cotidiana envolvida no cuidar/cuidado de enfermagem em cirurgia cardíaca. Consideramos que, dentro do cenário escolhido, enfermeiros são atores sociais que interagem no seu dia-a-dia de forma particular, rica em detalhes, tanto com clientes como com outros profissionais da área da saúde. Assim, a etnometodologia permitiu interpretar os símbolos e significados da linguagem através dos conceitoschave: indicialidade, a prática e a noção de membro.

A indicialidade constitui o significado de determinados símbolos. Neste estudo, relacionam-se a palavras, a aproximação corporal e os gestos. A prática enfoca as atividades e as circunstâncias práticas e o raciocínio sociológico prático, abordando as situações corriqueiras do cotidiano; nesse caso, a linguagem utilizada no cotidiano por enfermeiros, que compõe a interação com outros atores sociais. E a noção de membro refere-se aos indivíduos dotados de um conjunto de modos de agir, métodos, atividades, de uma saber fazer, nesse estudo os enfermeiros. 8,10

0 termo etnometodologia refere-se à investigação das expressões utilizadas no cotidiano ou outras ações práticas. Assim, permite conhecer e compreender as atividades sociológico-práticas do dia-a-dia. Garfinkel ${ }^{10: 1}$ entendia os estudos etnometodológicos como aqueles que:

...tratam as atividades práticas, as circunstâncias práticas e o raciocínio sociológico prático como tópicos de estudo empírico e atribui as atividades banais do cotidiano dos indivíduos a mesma atenção e importância que se atribui aos acontecimentos extraordinários, tentando apreendê-las como fenômeno social.

Consideramos que este método se adequou perfeitamente ao objeto de estudo porque apreendeu os símbolos e significados da linguagem utilizada por enfermeiros no cotidiano. Dentro do cenário escolhido, enfermeiros são atores sociais que interagem no seu dia-a-dia de forma particular, rica em detalhes que expressam este cotidiano, o qual dominam totalmente, como saber do que quer que seja.

0 campo para pesquisa foi um Hospital no Município do Rio de Janeiro, de grande porte, na Enfermaria Semi-Intensiva de Cirurgia Cardíaca e Unidade de Terapia Intensiva Cardíaca. A escolha justifica-se pelo grande número de cirurgias realizadas nesse hospital, em torno de duas a três por dia, com total de 120 durante o período de coleta de dados; além de uma equipe de enfermagem composta por um grande número de enfermeiros, o que possibilita que a assistência prestada ao cliente seja realizada diretamente por eles. 0 serviço é equipado 
com aparelhagens de última geração, tais como monitores cardíacos, ventiladores mecânicos, oxímetros, bombas infusoras, balão intra-aórtico entre outros equipamentos. Dessa forma, equivale a qualquer outro serviço privado, não tendo diferenças com relação aos tipos de procedimentos médicos e de enfermagem realizados.

A coleta de dados foi realizada com enfermeiros que atuam nesses setores. Utilizamos a observação participante que buscou gerar dados descritivos a partir de um roteiro previamente elaborado para esse fim, compreendendo um total de 60 horas, e tivemos a oportunidade de esclarecer situações identificadas como significativas na linguagem cotidiana. Foram incluídos alguns profissionais da equipe de enfermagem e de saúde durante a comunicação com os enfermeiros. Vale ressaltar que todos assinaram o termo de consentimento livre e esclarecido A necessidade de participar como membros do grupo para compreensão da linguagem cotidiana e seus significados exigiu a técnica de observação participante para esse estudo etnometodológico, pois este coleta dados através da participação na vida cotidiana do grupo que estuda ${ }^{11}$

0 diário de campo foi utilizado para o registro, interpretação e descrição dos sujeitos, do cenário e dos fenômenos de pesquisa. As observações foram descritas conforme os acontecimentos (fenômenos de pesquisa) e realizadas até que se esgotassem os dados. Para a identificação e codificação, os registros receberam uma sigla $D C$ e numerais cardinais. Utilizamos uma câmera fotográfica de marca Canon e filmes da Kodak, pretos e brancos, para melhor apreender o fenômeno de observação de campo, buscando assim a expressão do cuidar da enfermeira através da linguagem visual fixa.

A fotografia constitui o objeto visível da ciência, ela é real, mostra algo que "estava ali", que existiu, caracteriza o presente, e não o passado ou o futuro. Além de registrar um fenômeno no momento exato de seu acontecimento, através da captação da imagem e expressão da realidade, esta é também uma forma de estimulação da comunicação, ou seja, tem sua própria linguagem ${ }^{12}$.

Vale ressaltar que respeitamos todos os termos éticos de realização de pesquisa científica previstos na Resolução 196/ 96, do Conselho Nacional de Saúde - MS, sobre pesquisa envolvendo seres humanos. Foram obedecidos os princípios referentes ao consentimento livre e esclarecido e garantido sigilo sobre a privacidade dos sujeitos, quanto aos dados envolvidos na pesquisa, e, para tal, utilizamos nomes fictícios nos registros de diário de campo. 0 estudo foi aprovado e autorizado pelo Comitê de Ética do Hospital Universitário Pedro Ernesto/Universidade Estadual do Rio de Janeiro.

Para a organização e análise dos dados produzidos, realizamos inicialmente a preparação do material a ser analisado, através da transcrição integral dos registros de diário de campo, com as respectivas correções gramaticais, conforme foram coletados. Para tal, utilizamos o programa de computador Microsoft Word (Windows) e armazenamos os arquivos em disquetes. As informações foram classificadas por análise temática, que descobriu os pontos-chave que compõem a linguagem e cuja presença ou freqüência de aparição significava alguma coisa para o objetivo analítico escolhido ${ }^{13}$.
Então fizemos a relação entre os temas encontrados através da observação participante com o objeto de estudo. Dessa forma, a análise dos dados seguiu as seguintes etapas: descrever os dados; relacionar os dados coletados ao referencial bibliográfico sobre o cuidar/cuidado em cirurgia cardíaca; e confrontar os dados com o referencial teórico. A discussão foi norteada pelos conceitos de cuidar/cuidado de Coelho (1999), cotidiano de Certeau (1994), e indicialidade, prática e noção de membro, de Garfinkel (1967).

Para atender ao rigor científico e à validação dos dados, três enfermeiras desta área de conhecimento fizeram a leitura dos resultados deste estudo e, posteriormente, elaboraram comentários de acordo com a sua prática.

\section{ANÁLISE E INTERPRETAÇÃO DOS RESULTADOS}

A vida social se constitui através da linguagem, não a linguagem dos gramáticos e dos lingüistas, mas a linguagem utilizada no cotidiano ${ }^{8,10}$. Os enfermeiros conversam, caminham, tocam, olham, sorriem. Para tal, usam símbolos e significados de uma linguagem compreendida entre os membros desse grupo. A linguagem que emerge desse cotidiano é totalmente compreendida, dentro da situação vivida, pelos próprios enfermeiros que estão inseridos nesse cotidiano, mas, se retirada desse contexto, fica de difícil entendimento por se afastar de uma compreensão mais ampla.

Vejamos durante a admissão do cliente em pós-operatório imediato em cirurgia cardíaca:

Abre-se a porta do CTI e entra um leito transportado por três profissionais vestidos de verde, eles entram andando rápido em direção ao Box cinco. As enfermeiras: Carla e Ana e o médico Paulo se aproximam do Box cinco. Eles todos conversam: - O médico fala: "ela não é diabética, mas está fazendo hipoglicemia, outro completa: "PAM = 6mmHg", o enfermeiro continua: "foi feito diurético, ela urinou $1600 \mathrm{ml}$, Potássio 2,2, por isso a gente não deu mais diurético. $(D C-1)$

Durante a admissão do cliente, a interação entre os profissionais da equipe de saúde é essencial, pois todos os dados referentes ao cliente no pré e transoperatório devem ser informados e trocados por profissionais que estarão responsáveis por seu cuidado no pós-operatório. A linguagem utilizada é técnica, e a fala é rápida. Os profissionais conversam, mas ao mesmo tempo acoplam o respirador ao cliente, realizam a monitorização cardíaca e de pressão arterial média, entre outros cuidados. Nesse momento, valores de exames laboratoriais são informados, assim como débito urinário e sanguíneo na sala de operações. É importante salientar que, mesmo durante a comunicação entre os profissionais, estes se mantêm atentos ao estado hemodinâmico do cliente, e em alguns momentos a conversa é interrompida para salientar que algo não está bem, como a pressão arterial média. No entanto, o tom de voz é mantido, ocorre apenas uma pausa após a informação e todos observam os valores de pressão arterial média através do monitor. 
A linguagem cotidiana utiliza o saber profissional, com símbolos técnicos, que estão incorporados de valores e terminologias biomédicas. Para a compreensão do quadro clínico do cliente, é necessário o conhecimento técnicocientífico que compõe o alicerce profissional fornecendo base para o cuidar/cuidado de enfermagem. Vejamos um outro momento que retrata a utilização de símbolos e significados técnicos:

A enfermeira Carla ajuda a residente de enfermagem Renata a colher nova amostra de sangue arterial. A residente pega a seringa com o sangue e sai. Logo depois volta e fala: "Acidose corrigida Carla." Então a enfermeira Carla se aproxima da cliente retira o termômetro e fala: $35,8 . .$. , está aquecida... (DC- 4)

A fala da residente de enfermagem Renata está associada ao fato de que esta estava colhendo sangue arterial e levando para análise, usando uma linguagem simplificada. Assim, retorna informando à outra enfermeira que, através da gasometria arterial, o problema que o cliente tinha, que era um desequilíbrio hidroeletrolítico, estava corrigido. Segurando um termômetro, a enfermeira Carla informa o grau Celsius da temperatura axilar do cliente e complementa com a sua própria conclusão da verificação, considerando o contexto em que estão inseridos. Em outro momento, a enfermeira Carla faz um comentário que não teria nenhum sentido se estivesse isolado da situação vivida. Como segue:

A enfermeira Carla colhe o sangue e faz o teste, e fala: "Agora deu certo, deu HIGH". (DC- 05)

A palavra "high" significa "alta" em inglês, logo assimilado e transmitido como algo alterado. Como o aparelho utilizado para realização da glicemia capilar não é nacional, quando os valores ultrapassam $400 \mathrm{mg} / \mathrm{dl}$, este informa apenas HIGH. Assim na vida de todos os dias, em um centro de terapia intensiva cardíaco, a palavra HIGH tem um significado científico de alteração, de modificç̧ão, de elevado, alto.

Em outro momento:

A enfermeira Ana fala: "Só tem esse dreno, com ele não consigo ordenhar. Um dos cirurgiões mexe com a cabeça para cima e para baixo. Enquanto conversam, as enfermeiras conectam o cabo do monitor cardíaco nos eletrodos, abaixam o dreno e o coletor de diurese e organizam os equipos de soro e soros. Um médico residente vestido de verde conecta o tubo orotraqueal ao respirador inter 5. (DC - 2)

No dia-a-dia, algumas técnicas utilizadas rotineiramente acabam recebendo denominações que são utilizadas por toda a equipe de saúde. É o caso da "ordenha dos drenos". Essa técnica se assemelha ao ato de ordenhar leite de uma vaca. $\mathrm{Na}$ realidade, a enfermeira faz uma pressão negativa, com os dedos no dreno torácico, facilitando a saída do sangue e impedindo a formação de coágulos no seu interior.

Embora uma palavra tenha um significado de acordo à situação vivenciada, tem igualmente um significado distinto em toda a situação particular em que é usada? ${ }^{\text {?1 }} 0$ domínio dessa linguagem cotidiana faz com que os profissionais não se dêem conta de que utilizam palavras e gestos muitas vezes não compreendidos por pessoas que não são membros deste grupo $^{8,10}$. Ou que apresentam significados diferenciados na sociedade em geral, fazendo parte de uma linguagem cotidiana de outros grupos. Como podemos verificar quando:

A enfermeira Tânia é chamada por um auxiliar de enfermagem para atender ao telefone. Após desligar ela se aproxima do enfermeiro Tadeu e chama: "Tadeu". Ele olha para ela, que faz sinal com os braços, cruzandoos, fechando e abrindo. Depois faz o número 2 com os dedos. E fala: "na sala". Ele mexe a cabeça para cima e para baixo e caminha em direção ao posto. (DC -3)

A enfermeira Tânia foi chamada ao telefone para receber uma informação. Ao desligá-lo, ela chama o enfermeiro Tadeu. Através de gestos manuais, ela comunica a ele que o cliente que estava sendo operado (e era a segunda cirurgia daquele dia, por isso o "2") foi a óbito, por isso cruza os braços, em sinal de "acabou". Ele, também através de gestos, responde em sinal afirmativo. Para o entendimento deste gesto, foi necessária a confirmação deste dado ao questionar à enfermeira Tânia pessoalmente sobre a informação que dera ao enfermeiro Tadeu.

Para cada membro, o significado de sua linguagem cotidiana depende do contexto em que esta linguagem aparece ${ }^{8,10}$. Isto quer dizer que, caso a enfermeira Tânia tivesse feito o mesmo gesto, em outra situação, ou com outra pessoa, que não fosse membro deste grupo, provavelmente esta pessoa não entenderia dessa forma. 0 trecho abaixo mostra uma situação em que a linguagem utilizada está totalmente associada à situação do momento.

Outros dados mostram como a linguagem cotidiana tem 0 seu significado, dependendo do contexto em que aparece. Vejamos:

A estagiária fala para a enfermeira: "A PAM não está boa". A enfermeira Tânia responde: "Então vamos lavar". A estagiária pega o frasco de soro e uma seringa. (DC - 06)

Em outro momento:

A enfermeira Carla se aproxima da enfermeira Ana e fala: A diurese aqui está diminuindo, a PAM aumentoue está em Nove. Ana pergunta: "E ela superficializou alguma coisa?" Carla responde: "Já, ela está mexendo membros superiores". (DC - 07)

Nas duas situações descritas acima, as enfermeiras, ao se referirem à pressão arterial média, utilizam apenas as inicias PAM. Muitas informações são trocadas entre os enfermeiros na vida de todos os dias, o que faz a linguagem em cirurgia cardíaca rica em detalhes, que são entendidos sem dificuldades por todos os membros deste grupo.

Ao perguntar se o cliente "superficializou", a enfermeira Ana se referia ao nível de consciência deste cliente. Esta informação se confirma na resposta da Carla, que explica que o cliente já está movendo os membros superiores.

Essas expressões mostram que as palavras só ganham o seu sentido "completo", ou seja, real no seu contexto de produção, quando estão "indexadas" a uma situação de intercâmbio lingüístico. 0 significado de uma determinada palavra provém de fatores contextuais, como a intenção imediata do locutor, a relação que mantém com o ouvinte, suas conversações passadas ${ }^{10}$.

Assim, a linguagem do cuidar em cirurgia cardíaca não vai ocorrer sempre da mesma forma. Esta vai depender do contexto 
em que aparece, por quem é falada e para quem é falada. Vejamos em outro momento:

A enfermeira Laura se aproxima do leito e, mexendo nos frascos de soro, pergunta: "Entrou bicarbonato para ela?". 0 auxiliar de enfermagem responde: "Eles pediram 100 $\mathrm{ml}$ de bica. Ela começa a retirar o ar do equipo de soro e o fecha". Neste momento o enfermeiro Eduardo chega e pergunta: "Eles pediram mais?" E a enfermeira Laura responde: "Não, estou só fechando". E se afasta indo em direção ao posto de enfermagem. (DC - 09)

A enfermeira ao falar com o auxiliar de enfermagem utiliza uma linguagem técnica. Já a mesma palavra, quando falada pelo auxiliar de enfermagem, ganha um sentido informal e simplificado, que se refere ao bicarbonato de sódio apenas como "bica". Apesar de todos os profissionais estarem inseridos no mesmo cenário, a forma de se comunicar, ou seja, a linguagem utilizada pelos atores sociais depende da interrelação entre locutor e ouvinte, da situação social e profissional em que aparece. Percebemos que a linguagem da vida de todos os dias entre enfermeiros é uma linguagem técnica, que utiliza palavras científicas, nomes de medicações, números, siglas e abreviações. Vejamos outro momento que apresenta a linguagem cotidiana:

A enfermeira Ana fala: "O paciente é pós-op. de revascularização do miocárdio, hipertenso, já aumentamos o tridil para $18 \mathrm{ml} / \mathrm{h}$, mas a $P$ A continua alta." (DC - 10)

A enfermeira Ana explica que o paciente está em pósoperatório de revascularização do miocárdio e o seu quadro clínico ao dizer "pós - op", "hipertenso", "aumentamos o tridil”, "PA continua alta". Existe certa cumplicidade entre o locutor e o ouvinte, como podemos observar abaixo:

0 médico se aproxima do leito e pergunta: "Já foi instalada a insulina?" A enfermeira Carla, que estava organizando as medicações que estavam fluindo por via endovenosa através da bomba infusora, responde sem olhar para ele: "não". Ele diz: "É urgente..." (silêncio)... "se não colocar ele vai piorar a cetoacidose e parar". Ela continua organizando e fala: "Não tem via disponível, só quando acabar o sangue, se não vai empurrar a noradrenalina." Ele sai. Elas continuam arrumando o cliente, desenrolando os equipos de soro, esticando o lençol. 0 médico volta e fala para as enfermeiras: Prepara o material para eu pegar uma veia profunda. E sai. $(D C-13)$

Em momentos de crise, as situações de atrito carregam uma linguagem rica em símbolos, que caracterizam a interação que acontece com poucas palavras. A comunicação não-verbal entre os profissionais aconteceu no momento em que os profissionais viraram o rosto e se mantiveram em silêncio. 0 corpo fala sem palavras e expressa a linguagem silenciosa da comunicação não-verbal ${ }^{14}$. Através dele nós dizemos e recebemos muitas mensagens. Através do nosso corpo, estamos a todo tempo emitindo algum tipo de mensagem, mesmo que não esteja de acordo com as mensagens que emitimos através da comunicação não-verbal. Como segue:
A enfermeira levanta e se aproxima da cliente de forma que esta a veja e fala: "Oi bonitinha, a senhora tem que ficar acordada, para respirar sozinha". (DC - 17)

Esta é uma outra linguagem cotidiana do cuidar em cirurgia cardíaca. Os profissionais da equipe de enfermagem utilizam com freqüência nomes carinhosos para chamar sua clientela. Vejamos:

"Seu Antônio fica calmo já acabou a cirurgia." (DC-18)

Outras vezes o que se verifica é que o cliente é chamado pelo nome. Esta linguagem caracteriza a individualidade do cuidar em cirurgia cardíaca, na qual, apesar da utilização de uma linguagem técnica, se respeita cada ser humano.

\section{CONCLUSÃO}

0 cuidar/cuidado de enfermagem em cirurgia cardíaca, como prática social, detém uma quantidade inesgotável de símbolos e significados, ligados ao fazer profissional, que, de acordo com a situação vivida, dão sentido a realidade que os envolve.

A linguagem foi descrita como uma forma especial de cuidar em cirurgia cardíaca que inclui a comunicação verbal e nãoverbal. Assim, a linguagem técnica é aquela que compreende palavras científicas, conhecidas como termos técnicos, que são aprendidos durante a formação profissional. As siglas e abreviações caracterizam a necessidade de tornar rápidas a escrita e a fala. 0 silêncio e os gestos indicam a forma como 0 corpo fala sem palavras, atitude utilizada com freqüência neste cotidiano, sendo compreendido perfeitamente pelos membros do grupo e utilizados geralmente quando as questões éticas impossibilitam a comunicação verbal. Algumas palavras com significado distinto são utilizadas por semelhança com ações realizadas fora do contexto hospitalar.

Os enfermeiros trocam informações sobre os clientes com o objetivo de fornecer continuidade ao cuidado de enfermagem de um plantão para outro. A linguagem utilizada pelos atores sociais se apresenta de acordo com a situação, considerando os atores que estão interagindo. Estes têm uma forma especial de se comunicar, que se modifica de acordo com as condições do cliente. Mas o cotidiano mostra também a linguagem utilizada no dia-a-dia pelos profissionais da saúde, que apresentam uma forma peculiar de se comunicar envolvendo gestos e palavras. Uma linguagem com abreviações que demonstram a correria e agitação do setor. Esta linguagem, rica de símbolos e significados, é totalmente entendida pelos membros do grupo e se apresenta de forma natural pelos atores. A linguagem técnica e científica não é de domínio do cliente, de forma que este não compreende, no sentido correto, a linguagem utilizada entre os profissionais da saúde, podendo fazer interpretações errôneas dos cuidados prestados.

Assim, este estudo propõe uma reflexão sobre a importância de utilizarmos no cotidiano uma linguagem compreendida não só pelos enfermeiros, mas também pelo cliente. Compreender que o cotidiano do cuidar do enfermeiro em cirurgia cardíaca inclui clientes, mas o cotidiano de cada cliente não possui enfermeiros, é essencial para que a linguagem seja uma ferramenta do cuidar/cuidado de enfermagem. 


\section{Referências}

1.Certeau M. A invenção do cotidiano: artes de fazer. Petrópolis (RJ): Vozes; 1994.

2. Coelho MJ, Carvalho V, Figueiredo, NMA. 0 socorro, o socorrido e o socorrer: cuidar/cuidados em enfermagem de emergência. Rio de Janeiro (RJ): EEAN/UFRJ; 1999.

3. Cavalcanti ACD, Coelho MJ. 0 cotidiano do cuidar de enfermagem em cirurgia cardíaca: a interação como ferramenta do cuidado. Rio de Janeiro (RJ): EEAN/UFRJ; 2006.

4. Silva MM, Santos NLP. Avaliação retrospectiva da práxis do processo de enfermagem no cuidado ao idoso em cirurgia cardíaca. Esc Anna Nery Rev Enferm 2005 dez; 9 (3): 388-96.

5. Santoro DC. 0 cuidado de enfermagem na unidade coronariana: um ensaio sobre a dimensão da subjetividade do cuidar [tese de doutorado]. Rio de Janeiro (RJ): Escola de Enfermagem Anna Nery/ UFRJ, 2000.

6. Berlo DK. 0 processo da comunicação: introdução à teoria e à prática. $9^{a}$ ed. São Paulo (SP): Martins Fontes; 1999.

7. Carvalho V, Silva SL. 0 interacionismo simbólico e a pesquisa em enfermagem. Esc Anna Nery Rev Enferm 2005 dez; 9 (3): 441-50.

8. Coulon A. Etnometodologia. Petrópolis (RJ): Vozes;1995.

9. Bogdan RC, Biklen SK. Investigação qualitativa em educação: uma introdução à teoria e aos métodos.Porto (PT): Porto Ed; 1994.
10. Garfinkel H. Studies in ethnomethodology. New Jersey(USA): Prentice-Hall;1967.

11. Becker H. Método de pesquisa em ciências sociais. São Paulo (SP): Hucitec; 1994.

12. Barthes R. A câmara clara. Rio de Janeiro (RJ): Nova Fronteira; 1984.

13. Bardin L. Análise de conteúdo. Lisboa(PT): Ed 70; 1977.

14. Weil P, Tompakow R. 0 corpo fala: a linguagem silenciosa da comunicação não-verbal. Petrópolis (RJ): Vozes; 2000.

\section{Sobre as Autoras}

\section{Ana Carla Dantas Cavalcanti}

Doutoranda em Enfermagem pela Escola de Enfermagem Anna Nery, Universidade Federal do Rio de Janeiro. Professora Assistente da Escola de Enfermagem Aurora de Afonso Costa, Universidade Federal Fluminense.

\section{Maria José Coelho}

Professora Adjunta da Escola de Enfermagem Anna Nery, Universidade Federal do Rio de Janeiro. Coordenadora do Grupo de Pesquisa Cuidar/Cuidado de Enfermagem. Pesquisadora do CNPq. 